\title{
Client outcomes across counselor training level within a multitiered supervision model
}

\author{
Scott J. Nyman \\ Michigan State University, snyman@genesys.org \\ Mark A. Nafziger \\ Utah State University, mark.nafziger@usu.edu \\ Timothy B. Smith \\ Brigham Young University, tbs@byu.edu
}

Follow this and additional works at: https://scholarsarchive.byu.edu/facpub

Part of the Counseling Psychology Commons

\section{Original Publication Citation}

Nyman, S. J., Nafziger, M. A., \& Smith, T. B. (2010). Client outcomes across counselor training level within a multi-tiered supervision model. Journal of Counseling and Development, 88 , 204-209.

\section{BYU ScholarsArchive Citation}

Nyman, Scott J.; Nafziger, Mark A.; and Smith, Timothy B., "Client outcomes across counselor training level within a multitiered supervision model" (2017). Faculty Publications. 2021.

https://scholarsarchive.byu.edu/facpub/2021

This Peer-Reviewed Article is brought to you for free and open access by BYU ScholarsArchive. It has been accepted for inclusion in Faculty Publications by an authorized administrator of BYU ScholarsArchive. For more information, please contact ellen_amatangelo@byu.edu. 
Nyman, S. J., Nafziger, M. A., \& Smith, T. B. (2010). Client outcomes across counselor training level within a multi-tiered supervision model. Journal of Counseling and Development, 88, 204-209.

Client Outcomes Across Counselor Training Level

Within a Multi-Tiered Supervision Model

Scott J. Nyman

Genesys Regional Medical Center, Grand Blanc, Michigan

Mark A. Nafziger

Counseling Center, Utah State University

Timothy B. Smith

Department of Counseling Psychology, Brigham Young University 


\begin{abstract}
Student trainees in graduate counseling programs provide mental health services to the public, but trainees may not provide the same quality of services as professional staff. Three years of outcome data were examined to evaluate treatment effectiveness at a public university counseling center that utilized a multi-tiered supervision model consisting of professional staff, pre-doctoral interns, and practicum students. Clients $(N=$ 264) completed self-report inventories of psychological distress at intake and again after the sixth session. Clients demonstrated significant improvement on all dependent measures, with no significant differences between those seen by professional staff vs. supervised trainees. Results appear to provide preliminary support for the clinical effectiveness of a multi-tiered supervision model. Limitations and implications for future inquiry are discussed.
\end{abstract}

Key Words: Counselor training, supervision, effectiveness, and outcome evaluation. 


\section{Client Outcomes across Counselor Training Level Within a Multi-Tiered Supervision Model}

A symbiotic relationship has long existed between mental health service providers and graduate student trainees seeking real-world counseling experience. Training sites offer graduate students invaluable opportunities to refine counseling skills, gain professional experiences, and receive expert supervision (Bernard \& Goodyear, 1998; Boggs \& Douce, 2000; Krasner, Howard, \& Brown, 1998). In return, these training sites receive free or low-cost labor from the graduate student trainees (Holland, 1998). In the current climate of increasing financial pressures and clinical demands placed on service providers (Constantine \& Gloria, 1998), the use of graduate student trainees has become so commonplace that few scholars question the practice. In this paper, we evaluate the assumption that counseling services provided by student trainees under close supervision result in equivalent client outcomes compared to services provided by licensed professionals.

A recent review of the counseling outcome literature concluded that "there have been surprisingly few research studies in the area of experience, training, and client outcome” (Lambert, 2005, p. 861). Studies that have endeavored to evaluate client outcome across counselor training level have yielded mixed results (Stein \& Lambert, 1995). While several reports suggest that counselor experience is not crucial to client outcome (Michael, Huelsman, \& Crowley, 2005; Propst, Paris, \& Rosberger, 1994), other reports favor experienced counselors (Callahan \& Hynan, 2005). Research has shown that experienced counselors conceptualize clients with greater depth and complexity (Mayfield, Kardash, \& Kivlighan, 1999), possess more highly developed cognitive, emotional, and relational characteristics (Jennings \& Skovholt, 1999), and experience 
fewer client drop-outs than do novices (Stein \& Lambert, 1995). In particular, novice counselors may display heightened anxiety, which can be detrimental to counseling interventions and the counselor-client relationship (e.g., Kelly, Hall, \& Miller, 1989). Under some circumstances, counselor experience level (Roth, 2003) and degree of trainee experience (Driscoll et al., 2003) can be significant predictors of client improvement. However, the overall magnitude of the differences between counselors and trainees in terms of client outcomes has not been established in the literature (Lambert, 2005).

Counselor training sites are responsible for the quality of mental health services that they provide to their clients. To compensate for the potential limitations in the effectiveness of clinical services provided by trainees, training sites implement several resource-intensive procedures. Most notably, training sites provide trainees with direct clinical supervision, which often includes both individual and group meetings with licensed professional staff. Typically, the training site will also develop and maintain supervision guidelines with accompanying oversight to ensure adequate models and contingencies to address challenges, such as trainee impairment and remediation (Gizara \& Forrest, 2004; Forrest, Elman, Gizara, \& Vacha-Haase, 1999). Ideally, training sites will also regularly evaluate client outcomes to document that the supervised counseling services provided by trainees are effective. Occasionally, training sites must pursue additional funding due to the challenge of obtaining third-party reimbursement for unlicensed counselors (Constantine \& Gloria, 1998). Finally, training sites must maintain close working relationships with the trainees’ university academic programs. All of these activities require extensive administrative efforts. Therefore, an inevitable consequence of involving trainees in clinical service provision is the shifting of experienced 
professional staff to greater administrative and supervisory roles. The most experienced counselors may end up seeing fewer clients.

To overcome the disadvantage of reducing direct client service hours among experienced counselors, several training sites have implemented a multi-tiered supervision model, consisting of personnel with varying degrees of experience: licensed doctoral level professional staff, postdoctoral fellows, pre-doctoral interns, and practicum students. Supervision is hierarchical, such that licensed staff members supervise fellows and interns, who subsequently supervise less experienced practicum students. Interns and fellows receive additional supervision from the licensed staff for their supervisory work with the practicum students. With post-doctoral fellows and/or pre-doctoral interns providing supervision to practicum students, professional staff members can retain more hours for direct client services than in traditional arrangements where professional staff provide direct supervision to all trainees. Multi-tiered supervision therefore appears to offer training sites a cost-effective avenue for providing mental health services while at the same time providing supervised experience in clinical supervision for advanced trainees. However, empirical analyses are needed to evaluate the effectiveness of counseling services provided by trainees under this multi-tiered supervision model.

The purpose of the present study is to extend the counseling training and supervision literature through the evaluation of outcome data from a training site that employed a multi-tiered supervision model. Specifically, the present study reports client outcomes across counselor level of training, with beginning practicum students supervised by pre-doctoral interns and professional staff and with pre-doctoral interns supervised by licensed professional staff. We tested the hypothesis that clients seeking 
services from a multi-tiered training center will demonstrate significant improvement in psychological functioning regardless of counselor training level.

Method

Participants. Participant data were culled from a mid-size public university counseling center in the Western United States. Intake data were obtained from 444 clients, with 264 (59\%) clients completing at least 6 counseling sessions, which we set as the minimum number of sessions required for inclusion in outcome analyses. These participants were an average of 23.9 years old at intake, with $67 \%$ being female. Participants were 20\% freshmen, 17\% sophomores, 26\% juniors, $23 \%$ seniors, and $14 \%$ graduate students. The sample consisted of 91\% European Americans, 3\% International Students, 3\% Hispanic/Latino Americans, 2\% Asian Americans, 1\% African Americans, and 1\% Native Americans. The demographics of participants who completed less than 6 sessions did not differ $(p>.05)$ from those who completed 6 or more sessions

Materials. We selected two instruments that were empirically supported for use with college students, the College Adjustment Scales (CAS; Anton \& Reed, 1991) and the Outcome Questionnaire (OQ-45; Lambert, Hansen, et al., 1996). The CAS is a 108 item self-report inventory composed of nine scales: Anxiety, Depression, Suicidal Ideation, Substance Abuse, Self-Esteem, Interpersonal Problems, Family Problems, Academic Problems, and Career Problems. Initial data from 1,146 U.S. university students demonstrated subscale internal consistency ranging from .80 to .92 (Anton \& Reed, 1991). A subsequent study reported evidence of convergent and discriminant validity (Wiswell, 1995), and another study found that the CAS significantly differentiated between clinical and non-clinical samples (Nafziger, Couillard, Smith, \& Wiswell, 1998). In addition, counselors generally supported the CAS for confirming 
client presentation at intake (Nafziger, Couillard, \& Smith, 1997). Because the counseling center evaluated in the present study provided individual mental health services, rather than academic advisement, career counseling, family therapy, or substance abuse treatment, data on the CAS Family Problems, Substance Abuse, Academic Problems, and Career Problems subscales were not relevant outcomes and were therefore omitted from analyses.

The OQ-45 is a brief 45-item self-report inventory of current psychological functioning designed to be cost effective, sensitive to change over time, and applicable to varying degrees of psychological distress (Lambert, Burlingame, et al., 1996). Although initially designed to measure factors of symptomatic distress, interpersonal problems, and social role dysfunction, subsequent research appears to support a single factor construct using a global score (Mueller, Lambert, \& Burlingame, 1998). Psychometric properties for the OQ-45 appear acceptable with respect to 3-week test-retest reliability (.84), internal consistency (.93), and concurrent validity (Lambert, Burlingame, et al.). In addition, the OQ-45 has demonstrated sensitivity to client improvement within university counseling center settings (Vermeersch et al., 2004).

Procedure. Prior to an initial intake session, students seeking services from the university counseling center completed the CAS and OQ-45. Following intake, the OQ45 was administered every 3rd session, while the CAS was administered every 6th session. During the 3-year data collection period the counseling center was staffed with 5 doctoral-level licensed mental health professionals, 9 pre-doctoral interns (3 per year), and 18 practicum students (6 per year). A multi-tiered supervision model was utilized in which professional staff supervised pre-doctoral interns and first-semester practicum students. Pre-doctoral interns supervised second-semester practicum students and 
received additional supervision specific to that work from licensed professionals. The counseling center operated an internship program fully accredited by the American Psychological Association and abided by all accreditation stipulations. All trainees videotaped and reviewed counseling sessions with supervisors in weekly individual and group supervision sessions.

\section{Results}

As a preliminary step, it was important to verify whether clients assigned to practicum students, pre-doctoral interns, and licensed professional staff differed in terms of their initial symptom severity. We therefore conducted a multivariate analysis of variance (MANOVA) using intake scores on all dependent measures (the OQ-45 and all CAS subscales) across experience levels. The results were not statistically significant, Wilks’ Lambda $=.97, F(12,870)=1.2, p=.27$, indicating that clients had a similar level of self-reported symptoms at intake across the three groups of counselors.

To determine if there were differences in the magnitude of client improvement as a function of counselor training level, we conducted a repeated measures MANOVA using scores on the OQ-45 and CAS subscales at both intake and follow-up. The withinsubjects effects of time (intake to follow-up) reached statistical significance for the multivariate test, Wilks’ Lambda $=.74, F(6,167)=9.7, p<.0001$, and for all univariate tests across the OQ and CAS subscales (see Table 1). However, neither the betweensubjects effects for the type of therapist (practicum students, pre-doctoral interns, and licensed professional staff) nor the interaction effect between the type of therapist and time reached statistical significance, Wilks’ lambda $=.92, F(12,334)=1.23, p=.26$, and Wilks' lambda $=.92, F(12,334)=1.19, p=.28$, respectively (see Table 2$)$. Even though clients reported significant decreases in symptoms across a wide variety of clinical 
assessments (Table 1), there were no differences in client outcomes across counselor training level using mean score data (Table 2).

Because previous authors (e.g., Lambert \& Bergin, 1994) have noted that analyses of mean score differences do not reveal trends within the data, we next conducted more specific analyses to disaggregate the type of changes in symptom severity experienced by individual clients. Using guidelines established by Lambert, Burlingame and colleagues (1996) on the OQ-45, we classified clients into one of four groups based on scores from the initial and sixth session OQ-45, which has a clinical cut-off of 63.4 and a reliable change index of 14 . Recovered clients (20\%) had initial scores of 64 or higher that decreased by at least 14 points to a score of 63 or less. Improved clients (21\%) had intake scores that subsequently decreased by 14 points or more but were not yet less than the clinical cut-off score. Deteriorated clients (12\%) increased in their scores by at least 14 points. Unchanged clients (47\%) were those who did not meet any of the above criteria. We then performed a Chi-Square analysis across the categories of client outcome by counselor training level. The results were not statistically significant, $\Pi^{2}(6, N=264)=$ $4.3, p=.64$, confirming the findings from the analyses of mean score data.

A final set of analyses investigated client discontinuation of counseling as a function of counselor training level. Within the dataset, counselors had indicated whether the client had discontinued counseling without making progress toward counseling goals or without informing the counselor (i.e., "premature terminations”). It was possible that clients who had discontinued counseling did so for reasons related to dissatisfaction with the counselor. We therefore conducted a Chi-Square analysis with these data across counselor training level. The results did not reach statistical significance, $\Pi^{2}(2, N=444)$ $=2.1, p=.36$. Because it was possible that counselors did not reliably record whether a 
client discontinued counseling prematurely, we also evaluated differences across clients who had attended less than six sessions vs. more than six sessions. These results also did not reach statistical significance, $\Pi^{2}(2, N=444)=4.6, p=.10$. There was no evidence that clients discontinued counseling at higher rates if they were seen by a less experienced counselor.

\section{Discussion}

Clients in this study displayed improvements in psychological functioning that were independent of the training level of the counselor. Based on the data from the CAS and the OQ-45, clients who obtained services from a multi-tiered supervised training center experienced moderate symptom relief over six sessions regardless of whether they were seen by a licensed doctoral-level counselor, a pre-doctoral intern, or a practicum student. This finding appears to contradict some previous research that suggests trends favoring experienced counselors (e.g., Callahan \& Hynan, 2005; Driscoll et al., 2003; Roth, 2003). Although this finding also appears to contradict the basic assumption that experienced professionals should be more adept at facilitating client improvement than supervised trainees, there is increasing evidence that this assumption is unfounded (Lambert, 2005). It is important to note that the counselors in this study were all closely supervised and might demonstrate greater counseling effectiveness than would newly licensed counselors with similar experience who no longer receive expert supervision.

Nevertheless, the results of the present study should be interpreted cautiously when considering the inherent limitations of non-experimental research designs. We evaluated clinical effectiveness rather than efficacy, which requires greater experimental rigor (Seligman, 1995). For instance, a control group was not included nor did we involve concurrent treatment groups from multiple training centers. Studies comparing counselor 
effectiveness across experience levels may also be limited by the within-group variability of the highest training tier (Stein \& Lambert, 1995). Further, the data collection from a university counseling center located in the rural Western United States restricts the likelihood that the results may be generalized to other clinical settings, geographical regions, and client populations.

This study was also limited in that it only evaluated client outcome and termination data. Although we evaluated multiple outcome measures and although client outcomes and termination rates are ostensibly the most clinically salient dependent variables, they reveal only certain aspects of clients' experiences in therapy. It is likely client expectations, client trust, and a host of other variables relevant to the clientcounselor relationship moderate and/or mediate client outcomes. For example, it is possible that clients, who recognize a counselor as a novice, may compensate by altering their own expectations for improvement (e.g., expecting less assistance from a novice counselor and therefore being satisfied when they obtain a minimal gain). Similarly, if clients recognize a counselor as being inexperienced, they may decrease their trust in the counselor's ability to handle difficult issues and therefore restrict their discussion to superficial topics that involve minimal psychological risk, such that the clients obtain short-term symptom reduction rather than long-term remission. Moreover, client progress was only tracked over six sessions of counseling, so differences in client outcome may only become significant over longer courses of treatment. Given these several possibilities, future research is needed to not only confirm the findings of this study regarding client outcomes but to also evaluate other pertinent variables regarding client expectations and the client-counselor relationship. 
Furthermore, the present study did not evaluate the cost-effectiveness of multitiered supervision. This study also did not address the question of whether multi-tiered supervision is superior to direct supervision by licensed staff only. It remains for future research to investigate trainee skill acquisition within and across specific training models (Stein \& Lambert, 1995). Useful variables to consider would include trainees’ and supervisors' satisfaction ratings and the observed number and nature of apparent ethical violations. Any data supporting the cost-effectiveness of multi-tiered supervision could be completely undermined if other data conclusively demonstrate that ethical violations of greater severity occur when trainees are supervised by advanced trainees as compared to when trainees are supervised by licensed professionals.

Despite its limitations, the present study provides preliminary support for a multitiered supervision model and may serve as a catalyst for future evaluative studies across other supervision models. The results also provide notable findings regarding the nature of clinical effectiveness within a training environment. Counseling training centers provide invaluable clinical and professional growth opportunities for trainees as well as licensed supervisors. In many ways, supervised training sites provide foundational experiences for the clinical practice of future professionals. Given the magnitude of this influence-and given the commonplace use of trainees in providing clinical services to clients experiencing genuine distress-the dearth of research investigating client outcomes across counselor training levels (Lambert, 2005) seems a glaring omission in the counseling literature. It may be that researchers are loathe to face the possibility that the extensive efforts involved in educating graduate students to become licensed professionals results in no observable differences in client outcome. However, in the interest of empirical inquiry, we urge the field to squarely face the possibility that 
supervised novice counselors may be as effective as experienced counselors and to work more systematically in uncovering the many moderating and mediating variables associated with client outcome and client-counselor relationships. 


\section{References}

Anton, W. D., \& Reed, J. R. (1991). College adjustment scales: Professional manual. Odessa, FL: Psychological Assessment Resources, Inc.

Bernard, J. M., \& Goodyear, P. K., (1998). Fundamentals of clinical supervision (2 ${ }^{\text {nd }}$ ed.). Boston: Allyn \& Bacon.

Boggs, K. R., \& Douce, L. A. (2000). Current status and anticipated changes in psychology internships: Effects on counseling psychology training. The Counseling Psychologist, 28, 672-686.

Callahan, J. L., \& Hynan, M. T. (2005). Models of Psychotherapy Outcome: Are they applicable in training clinics? Psychological Services, 2, 65-69.

Constantine, M. G., \& Gloria, A. M. (1998). The impact of managed health care on pre-doctoral internship sites: A national survey. Professional Psychology: Research and Practice, 29, 195-199.

Driscoll, K. A., Cukrowicz, K. C., Reitzel, L. R., Hernandez, A., Petty, S. C., \& Joiner, T. E. (2003). Behavior Therapy, 34, 165-177.

Forrest, L., Elman, N., Gizara, S., \& Vacha-Haase, T. (1999). Trainee impairment: A review of identification, remediation, dismissal, and legal issues. Counseling Psychologist, 27, 627-686.

Gizara, S. S., Forrest, L. (2004). Supervisors’ experiences of trainee impairment and incompetence at APA-accredited internship sites. Professional Psychology: Research and Practice, 35, 131-140.

Holland, D. (1998). The cost-effective delivery of rehabilitation psychology services: The responsible utilization of paraprofessionals. Rehabilitation Psychology, 43, 232245. 
Jennings, L., \& Skovholt, T. M. (1999). The cognitive, emotional, and relational characteristics of master counselors. Journal of Counseling Psychology, 46, 3-11.

Krasner, R. F., Howard, K. I., \& Brown, A. S. (1998). The acquisition of psychotherapeutic skill: An empirical study. Journal of Clinical Psychology, 54, 895-903.

Kelly, K. R., Hall, A. S., \& Miller, K. L. (1989). Relation of counselor intention and anxiety to brief counseling outcome. Journal of Counseling Psychology, 36, 158162.

Lambert, M. J. (2005). Early response in psychotherapy: Further evidence for the common factors rather than "placebo effects.” Journal of Clinical Psychology, 61, 855-869.

Lambert, M. J., \& Bergin, A. E. (1994). The effectiveness of psychotherapy. In A. E. Bergin and S. L. Garfield (Eds.) Handbook of psychotherapy and behavior change (pp. 143-189). New York: Wiley.

Lambert, M. J., Burlingame, G. M., Umphress, V., Hansen, N. B., Vermeersch, D. A., Clouse, G. C., \& Yanchar, S. C. (1996). The reliability and validity of the Outcome Questionnaire. Clinical Psychology and Psychotherapy, 3, 249-258.

Lambert, M. J., Hansen, N. B., Umphress, V., Lunnen, K., Okiishi, J., Burlingame, G. M. (1996). Administration and scoring manual for the OQ-45.2. Stevenson, MD: American Professional Credentialing Services, LLC.

Mayfield, W. A., Kardash, C. M., Kivlinghan, D. M., Jr. (1999). Differences in experienced and novice counselor's knowledge models about clients: Implications for case conceptualization. Journal of Counseling Psychology, 46, 504-514. 
Michael, K.D., Huelsman, T. J., \& Crowley, S. L. (2005). Interventions for child and adolescent depression: Do professional counselors produce better results? Journal of Child and Family Studies, 14, 223-236.

Mueller, R. M., Lambert, M. J., Burlingame, G. M. (1998). Construct validity of the Outcome Questionnaire: A Confirmatory factor analysis. Journal of Personality Assessment, 70, 248-262.

Nafziger, M. A., Couillard, G. C., Smith, T. B., \& Wiswell, D. K. (1998). Normative data on the College Adjustment Scales from a university counseling center. Journal of College Student Development, 39, 283-289.

Nafziger, M. A., Couillard, G. C., \& Smith, T. B. (1997). An evaluation of the clinical utility of the College Adjustment Scales. College Student Journal, 31, 516-518.

Propst, A. P., Paris, J., \& Rosberger, Z. (1994). Do counselor experience, diagnosis, and functional level predict outcome in short term psychotherapy? Canadian Journal of Psychiatry, 39, 168- 176.

Roth, S. A., (2003). A program evaluation measuring the effectiveness of service delivery at a university counseling center. Dissertation Abstracts International Section A: Humanities and Social Sciences, 63 (12-A), pp. 4235.

Seligman, M. E., (1995). The effectiveness of psychotherapy: The Consumer Reports Study. American Psychologist, 50, 965-974.

Stein, D. M., \& Lambert, M. J. (1995). Graduate training in psychotherapy: Are therapy outcomes enhanced? Journal of Consulting and Clinical Psychology, 63, 182-196.

Vermeersch, D. A., Whipple, J. L., Lambert, M. J., Hawkins, E. J., Buchfield, C. M., \& Okiishi, J. (2004). Outcome Questionnaire: Is it sensitive to changes in counseling center clients? Journal of Counseling Psychology, 51, 38-49. 
Wiswell, D. K. (1995). Establishing the validity of the college adjustment scales (CAS) as outcome measures in a university counseling center: A test of construct and convergent validity. Unpublished doctoral dissertation, Utah State University, Logan. 
Table 1

Client OQ-45 and CAS Data at Intake and Follow-Up

\begin{tabular}{|c|c|c|c|c|}
\hline Measure & $\mathrm{M}(\mathrm{SD})$ & $\mathrm{M}(\mathrm{SD})$ & $F^{*}$ & $d^{* *}$ \\
\hline & Intake & Session 6 & & \\
\hline OQ-45 & $78.4(23.6)$ & $69.4(21.2)$ & 39.8 & .40 \\
\hline CAS Anxiety & $60.9(9.4)$ & $56.5(10.0)$ & 43.8 & .45 \\
\hline CAS Depression & $62.7(10.5)$ & $57.8(10.0)$ & 53.2 & .48 \\
\hline CAS Suicidal Ideation & $57.0(10.5)$ & $53.5(10.0)$ & 12.4 & .34 \\
\hline CAS Self-Esteem & $62.1(9.0)$ & $59.5(9.0)$ & 20.7 & .29 \\
\hline CAS Interpersonal & $57.3(9.4)$ & 54.9 (9.9) & 16.3 & .25 \\
\hline
\end{tabular}

Note: $*=F$-value from repeated measures analyses of variance. For all analyses $p<.001$. ** = standardized mean difference from intake to follow-up. 
Effective Treatment 19 
Effective Treatment 20 
Table 2

Means (and Standard Deviations in Parentheses) of Client OQ-45 and CAS Data at Intake and Follow-Up Across Counselor Training Level

\begin{tabular}{|c|c|c|c|c|}
\hline \multirow[b]{3}{*}{ Measure } & Practicum & Pre-doctoral & Professional & \multirow[b]{3}{*}{$F^{*}$} \\
\hline & Student & Intern & Staff & \\
\hline & $(n=47)$ & $(n=95)$ & $(n=122)$ & \\
\hline OQ-45 & & & & 0.1 \\
\hline Pre & $75.0(23.4)$ & $80.1(21.7)$ & $81.0(25.5)$ & \\
\hline Post & $67.9(23.2)$ & $70.1(19.5)$ & $69.5(22.0)$ & \\
\hline CAS Anxiety & & & & 0.3 \\
\hline Pre & $62.1(7.7)$ & $60.1(9.4)$ & $61.7(9.4)$ & \\
\hline Post & $57.0(7.9)$ & $56.2(8.6)$ & $56.3(11.2)$ & \\
\hline CAS Depression & & & & 0.5 \\
\hline Pre & $62.5(8.4)$ & $63.5(9.9)$ & $63.4(10.5)$ & \\
\hline Post & $58.8(8.9)$ & $58.6(8.7)$ & $56.9(10.6)$ & \\
\hline CAS Suicidal Ideation & & & & 1.4 \\
\hline Pre & $55.9(10.3)$ & $58.2(10.6)$ & $57.6(11.3)$ & \\
\hline Post & $52.2(8.5)$ & $55.2(9.8)$ & $52.6(10.2)$ & \\
\hline CAS Self-Esteem & & & & 0.3 \\
\hline Pre & $61.3(8.7)$ & $62.8(9.0)$ & $62.9(9.8)$ & \\
\hline Post & $59.0(8.6)$ & $60.2(7.4)$ & $59.5(9.6)$ & \\
\hline CAS Interpersonal & & & & 0.2 \\
\hline Pre & $57.0(8.4)$ & $57.8(8.7)$ & $57.3(10.7)$ & \\
\hline Post & $55.0(8.8)$ & $55.3(10.3)$ & $54.4(9.9)$ & \\
\hline
\end{tabular}

Note: $*=F$-value from repeated measures analyses of variance across counselor type.

For all analyses $p>.10$. 